\title{
A Flexible Logistics Distribution Hub Model considering Cost Weighted Time
}

\author{
Wenxue Ran, Zhe Zhang, and Sen Liu \\ School of Logistics, Yunnan University of Finance and Economics, Kunming 650221, China \\ Correspondence should be addressed to Sen Liu; liusencool@163.com
}

Received 14 March 2017; Revised 11 July 2017; Accepted 2 August 2017; Published 11 September 2017

Academic Editor: Allan C. Peterson

Copyright (c) 2017 Wenxue Ran et al. This is an open access article distributed under the Creative Commons Attribution License, which permits unrestricted use, distribution, and reproduction in any medium, provided the original work is properly cited.

\begin{abstract}
The delivery time of order has become an important fact for customers to evaluate logistics services. Due to the diverse and large quantities of orders in the background of electronic commerce, how to improve the flexibility of distribution hub and reduce the waiting time of customers becomes one of the most challenging questions for logistics companies. With this in mind, this paper proposes a new method of flexibility assessment in distribution hub by introducing cost weighted time (CWT). The advantages of supply hub operation mode in delivery flexibility are verified by the approach: the mode has pooling effects and uniform distribution characteristics; these traits can reduce overlapping delivery time to improve the flexibility in the case of two suppliers. Numerical examples show that the supply hub operation mode is more flexible than decentralized distribution operation mode in multidelivery cycles.
\end{abstract}

\section{Introduction}

Today, as the development of electronic commerce drives the increase of consumer demand, improving the flexibility of distribution hub to reduce the order-to-delivery time has become the primary challenge for distribution centers [1]. Due to the high time and financial costs, order delivery is considered an important activity of logistics distribution centers. Some studies have shown that the delivery time accounted for more than half of logistics services time [2].

The distribution hub is closely related to the efficiency of order delivery, so it has been a hot research topic in logistics researches for the last several decades, and scholars have used a variety of methods in their attempts to study distribution hub, including logistics hub location, optimization of logistics network, region partitioning, and supply chain performance evaluation of logistics hub. (i) Logistics hub location: Ebrahimi-zade et al. [3] used covering radius, a decision variable, to build new mixed integer model to hub covering problem of multiperiod single distribution hub. Mohammadi et al. [4] proposed a mixed integer programming model to reduce failure cost for disruption problem; a new hybrid metaheuristic algorithm is designed to solve and prove reliability of the model. Correia et al. [5] put forward a modeling framework to minimize the total expected transportation costs between logistics hubs for determining the best multiple allocation hub locations. Some scholars even used the geographical level and family choice to construct structuration criteria for sequential assessment or simultaneous assessment of hubs location [6]. (ii) Optimization of logistics network: Ghodratnama et al. [7] proposed a single distribution hub location model with the objective of total transportation and installation costs and also considered the effects of different modes of transport on greenhouse gas emissions. Yang et al. [8] used the new fuzzy random simulation technique and the multistart simulated annealing algorithm to optimize the intermodal hub-andspoke model to obtain the minimum mixed traffic cost and travel time. (iii) Region partitioning: the purpose is to divide the hubs in a certain area into several zones according to some rules. According to priority, the multistage logistics distribution network is divided into two-echelon logistics distribution region [9]. Anwar et al. [10] used spectral theory based graph partition to divide the density peak graph and obtain the different subnetworks, and results show that the proposed method is superior to the existing approach based 
on normalization. Franceschetti et al. [11] divided the distribution hub network by customer density to obtain the best combination of distribution hub partitions and number of vehicles. (iv) Supply chain performance evaluation of logistics hub: Bichou and Gray [12] proposed an approach that evaluates hub efficiency by directing port strategy towards relevant value-added logistics activities. Then Bichou [13] designed an integrative framework including traders affiliated with terminals as integrative benchmark to measure logistics hub performance by conceptualising hub from a logistics and supply chain management (SCM) approach. However, the most logistics centers usually measure output and resource utilization, while the use of comprehensive performance indicators is rare. Some scholars have made breakthroughs: Barros and Dieke [14] enhanced the performance of the least efficient airports by using data envelopment analysis (DEA). Cheng and Wang [15] constructed a platform that can be used to assess the integrated supply chain activities of enterprises, infrastructure, and institutional stakeholders in logistics hub.

To improve the efficiency of order distribution, some researchers studied the performance of logistics activities from the perspective of flexibility. Logistics flexibility is defined as an ability that reasonably uses a variety of resources in the storage, transportation, distribution, and other aspects to improve the response speed for customer's demand [1619]. In particular, Nigel [20] and Upton [21] have made pioneering works in the study of flexibility. The former defined the flexibility from three dimensions (range, time, and cost): (1) range, the state or behavior of systems; (2) time, the time consumption of transition between states; (3) cost, the cost of transition between states. Based on the study [20], Upton [21] proposed the uniformity of flexibility, which can keep the performances of the whole system consistent. Now, the research of logistics flexibility is mainly focused on the transportation planning and management, facilities management, and other logistics activities related to information processing, material transportation, inventory management, reverse logistics, tracking, and delivery [22]. In order to improve the manufacturing flexibility, Mansoornejad et al. [23] considered the product line configuration in the integration of supply chain. Papageorgiou [24] proposed an optimized supply chain model considering the effect of uncertainty on system flexibility. Even the two-stage stochastic programming method is used to improve the flexibility of logistics system $[25,26]$.

Nevertheless, the existing researches have some limitations: (i) most of them defined the definition and condition of delivery flexibility or used delivery flexibility as one of the assessment indicators to solve other problems. For example, the impact of the manufacturer's promise strategy on the flexibility of delivery was discussed in [27]. Li et al. [28] designed a pricing strategy to maintain a high delivery flexibility. Chen [29] made a path planning model to solve fuzzy flexible delivery and pickup problem. However, few studies have responded to the question: how to determine the delivery flexibility under known distribution center operation mode? (ii) There are some previous works which considered weight in the supply chain management; Li et al. [30] constructed the TOPSIS model based on entropy weight considering the short-term target, the design concept of strategic target, and the characteristics of synchronous supply chain. Kocaoğlu et al. [31] designed a TOPSIS evaluation model based on strategic objectives and business indicators and used analytic hierarchy process (AHP) to determine the weights of indicators. Ha et al. [32] focused on interdependencies among logistics hub performance measures and built a model to quantify the supply chain performance of hub by introducing weights of interdependent measures. In [33], the "slack time" was used to evaluate the flexibility of enterprises' supply chain. However, they constructed the indicators of flexibility evaluation only taking into account the company strategy, external environment, competitors' reflection, and so on. Compared with these macrofactors, the microfactors such as delivery cost and delivery time interval have been neglected; they are flawed for assessing the flexibility of the distribution center [20]. Therefore, in order to resolve the research gap, this paper proposes a new method of flexibility assessment in distribution hub considering cost weighted time. The cost weighted time introduces the delivery cost factor of order into slack time that can be more accurate to measure the effect of delivery cost on the delivery time. In multidelivery cycles, the numerical examples show that supply hub is more flexible than decentralized distribution operation mode.

The rest of the paper is structured as follows. Section 2 introduces the proposed new method. Section 3 presents our numerical example and discussion of results. The conclusions are presented in Section 4.

\section{The Method of Flexibility Assessment in Distribution Hub}

2.1. Problem Statement. Supply hub is also known as supplier hub, vendor-managed inventory (VMI) hub, which refers to the logistics distribution center located near the manufacturer and used to store the raw materials of supplier [34]. Unlike decentralized distribution mode, supply hub changes the relationship between manufacturers and suppliers from one-to-many to one-to-one, simplifying the operation processes [34]. Since the utilization of supply hub has already achieved good results in enterprise management practices [35-37], we validate the effectiveness of the new approach by comparing and analyzing the flexibility performance of decentralized distribution mode as Mode 1 and supply hub operation mode as Mode 2. In order to facilitate the study, we consider the simple supply chain structure of 1 manufacturer and 2 suppliers. Each distribution center of Mode 1 only delivers one raw material as shown in Figure 1. The hub of Mode 2 concentrates on two kinds of raw materials for management and distribution as shown in Figure 2.

In Mode 1, two suppliers of enterprises deliver raw materials to manufacturers through distribution center 1 and distribution center 2. The manufacturer's demands for different raw materials are decentralized. Through two separate distribution activities, manufacturer obtains the raw materials required, which greatly extends the order-to-delivery time. 


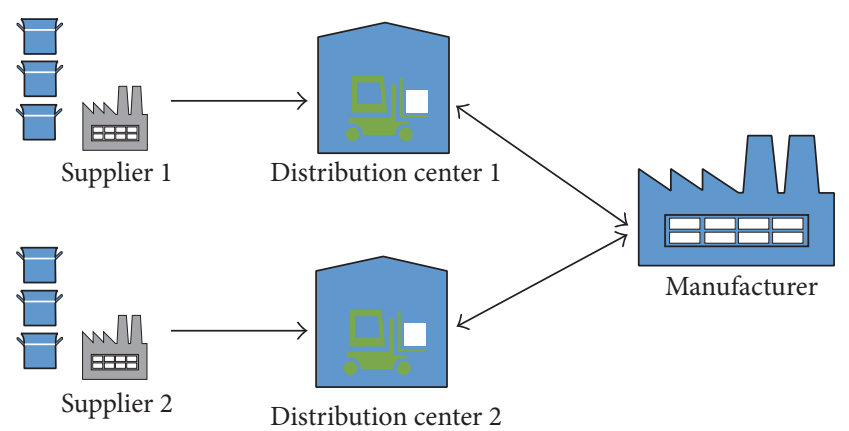

FIgURE 1: The decentralized distribution mode.

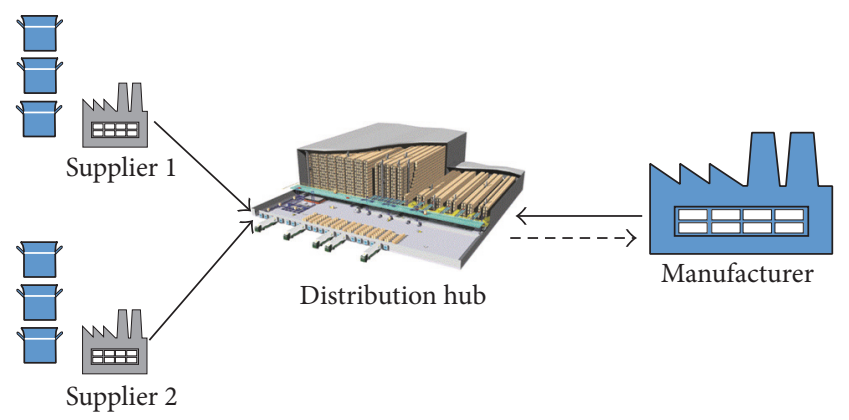

FIGURE 2: The supply hub operation mode.

In Mode 2, the raw materials of supplier 1 and supplier 2 are centrally delivered to one hub, and manufacturer only communicates with the hub when he needs raw material. This mode shortens the waiting time of manufacturer; it is conducive to reducing the cost of time.

In addition, based on the delivery principle of supply hub in $[38,39]$, there are several basic conditions for the model:

(1) Manufacturers issue orders to suppliers; then suppliers deal with the orders distribution according to the principle of "first come, first served."

(2) The operations of two modes follow the "cost-time" distribution principle to arrange the delivery of raw materials.

(3) In order to compare the distribution flexibility of two modes of operation in general, this paper ignores the delivery time between the supply chain nodes.

(4) We assume that there is no shortage phenomenon, which means that suppliers will meet the manufacturer's order requirements. System time starts at 0 time.

2.2. The Cost Weighted Time. In [33], the slack time is used to measure the flexibility of distribution, defining $t^{*}$ as the current time period and $L_{j}$ as the due date period (or the latest time period during which the delivery can be made) for job $j$; the total slack time is given by $\sum_{j=1}^{J}\left(L_{j}-t^{*}\right)$. Taking into account the impact of delivery costs on the flexibility of distribution [20], we obtained CWT as shown in (1) by introducing the cost of each distribution as weight into the slack time. The CWT contains two kinds of information: the slack time of each delivery and the cost of each delivery, meaning that CWT can be more accurate to measure the flexibility of distribution from the perspective of economy and timeliness. $\rho_{j}$ is determined by the remaining slack time $\left(\mathrm{LDT}_{j}-\mathrm{ET}_{j}\right)$. If the latest delivery time that manufacturers can tolerate is less than the earliest time that supplier can deliver $\left(\mathrm{LDT}_{j}-\mathrm{ET}_{j}<0\right)$, the delivery of order $j$ is not available

$$
\begin{array}{r}
\mathrm{CWT}=\frac{\sum_{j} \rho_{j} C_{j}\left(\mathrm{LDT}_{j}-\mathrm{ET}_{j}\right)}{\sum_{j} C_{j}}, \\
\rho_{j}= \begin{cases}1, & \mathrm{LDT}_{j}-\mathrm{ET}_{j} \geq 0, \\
0, & \mathrm{LDT}_{j}-\mathrm{ET}_{j}<0 .\end{cases}
\end{array}
$$

The weighted distribution flexibility $F$ is shown in

$$
F=\frac{\mathrm{CWT}}{\Delta t}=\frac{\sum_{j} \rho_{j} C_{j}\left(\mathrm{LDT}_{j}-\mathrm{ET}_{j}\right)}{\sum_{j} C_{j} \Delta t},
$$

$$
j=1,2, \ldots, n \text {. }
$$

If the remaining slack time $\left(\mathrm{LDT}_{j}-\mathrm{ET}_{j}\right)$ increases, the distribution system will be more flexible. Higher flexibility means that the ability of the system to deal with emergency orders will be stronger, and the responses of order delivery are quicker [30]. $t_{w}$ is a constant, CWT directly determines the weighted distribution flexibility $F$.

2.3. The Flexibility Assessment of Two Distribution Modes in Multidelivery Cycle. Logistics service provider's order delivery cost is 0 at the beginning of each delivery cycle. When the order delivery cost accumulates to a desired level of enterprise or the enterprise has a certain number of orders that the waiting time for delivering is $t_{w}$, this delivery cycle ends and the system enters the next delivery cycle. In this paper, we will analyze the specific situation of the first delivery cycle and then extend to the subsequent cycle to analyze and discuss CWT of two modes.

\subsubsection{The Flexibility Assessment of Two Distribution Modes in} the First Delivery Cycle. In the first delivery cycle, distribution system starts at 0 time. If the costs of all order delivery do not exceed $U_{i}$ in $t_{w}$, we can obtain $I_{i 1}=t_{w}$. On the contrary, If the costs of all order delivery exceed $U_{i}$ in $t_{w}$, the cumulative delivery costs can catch up to $U_{i}$ for the first time, and $I_{i 1}=$ $t^{*}<t_{w}$. We can get (3) after development as follows:

$$
I_{i 1}= \begin{cases}t^{*}, & z_{t_{w}}>U_{i}, \\ t_{w}, & z_{t_{w}} \leq U_{i} .\end{cases}
$$


Since the probability distribution of $Z_{i}$ is continuous function of time, it can be integrated. According to (1) and (3), we can obtain CWT in the first delivery cycle as follows:

$$
\begin{aligned}
\mathrm{CWT}_{i 1} & =\frac{\rho_{1} \sum_{j} C_{j}\left(\mathrm{LDT}_{j}-\mathrm{ET}_{j}\right)}{\sum_{j} C_{j}} \\
& =\rho_{1} \frac{\int_{0}^{+\infty} z_{i} g\left(z_{i}\right) d z_{i} \cdot \int_{0}^{I_{i 1}}\left[t_{w}-I_{i 1}+t\right] d t}{\int_{0}^{I_{i 1}} \int_{0}^{+\infty} z_{i} g\left(z_{i}\right) d z_{i} d t} \\
& =\rho_{1}\left(-\frac{1}{2} I_{i 1}+t_{w}\right) .
\end{aligned}
$$

Since $I_{i 1}$ is a piecewise function, the demarcation point $U_{i}$ is introduced into the probability distribution function of $Z_{i}$. Setting up $\alpha=\Phi\left(\left(U_{i}-\mu_{i t}\right) / \sigma_{i t}\right)$ and $\beta=\left(\sigma_{i t} /\right.$ $\sqrt{2 \pi}) e^{\left(\left(U_{i}-\mu_{i t}\right) / \sigma_{\pi}^{2}\right)^{2}}$, then we can obtain $E\left(I_{i 1}\right)$ by approximate calculation:

$$
\begin{aligned}
E\left(I_{i 1}\right)= & E\left(t^{*}\right) \times p\left(z_{t_{w}} \mid z_{t_{w}}>U_{i}\right)+E\left(t_{w}\right) \\
& \times p\left(z_{t_{w}} \mid z_{t_{w}} \leq U_{i}\right) \\
= & \frac{U_{i}(1-\alpha)}{\mu_{i t}+\beta /(1-\alpha)}+\alpha t_{w} .
\end{aligned}
$$

The results of (5) are complex, in order to facilitate the analysis and derivation, we assume $U_{i}=\mu_{i t}$ (the ideal delivery cost of triggering distribution is equal to the average material delivery cost in the period of $\left.t_{w}\right)$ and $\alpha=\Phi\left(\left(U_{i}-\mu_{i t}\right) / \sigma_{i t}\right)=$ 0.5 . This assumption is practical and the similar assumption has been documented by [19]. In Mode 2, $U_{1}=\mu_{1 t}$ and $U_{g h}=$ $\mu_{1 t}+\mu_{2 t}$ are hypothetical conditions.

According to the above assumptions and (5), the following can be obtained:

$$
\begin{aligned}
E\left(I_{i 1}\right) & =\frac{U_{i}(1-\alpha)}{\mu_{i t}+\beta /(1-\alpha)}+\left.\alpha t_{w}\right|_{\alpha=0.5, \beta=\sigma_{i t} / \sqrt{2 \pi}} \\
& =\frac{0.25 U_{i}}{0.5 U_{i}+\beta}+0.5 t_{w} .
\end{aligned}
$$

Taking (4) into (6), we can obtain $E\left(\mathrm{CWT}_{i 1}\right)$ as follows:

$$
\begin{aligned}
E\left(\mathrm{CWT}_{i 1}\right) & =E\left[\rho_{1}\left(-\frac{1}{2} I_{i 1}+t_{w}\right)\right] \\
& =\rho_{1}\left(-\frac{1}{2} E\left(I_{i 1}\right)+t_{w}\right) \\
& =\rho_{1} t_{w}\left(\frac{-0.125 U_{i}}{0.5 U_{i}+\beta}+0.75\right) .
\end{aligned}
$$

Due to the fluctuations of delivery cost, $I_{i j}$ may be unstable in the first distribution cycle. $I_{i j}$ and CWT are negatively correlated; they are affected by the delivery costs. According to (6) and (7), there is a direct relationship between expected value of $\mathrm{CWT}$ and $\varphi_{i}$ (the ratio of mean and variance). Based on the principle of time cost distribution, the rapid increase of delivery cost may make a single logistics service provider accumulate to affordable upper limit ahead of time and increase CWT. However, in the case of a large reduction in delivery cost, this situation will not affect the longest waiting time and CWT will not reduce to negative. It can be seen that the raising volatility will increase the expected value of CWT. Therefore, the expected value of CWT in Mode 2 is able to be obtained by (7). Considering the completeness of raw materials distribution, the CWT in Mode 1 is relatively complex. The analysis is as follows.

In Mode 1, there is a big difference in the delivery cost of two raw materials. The difference will cause the delivery time of the same batch order to be out of sync.

For Mode 1, the orders produced before $s_{11}$ are delivered after $s_{21}$, the orders produced between $s_{11}$ and $s_{21}$ are delivered after $s_{12}$, and so on. Due to the restriction of two distribution channels, the delivery time of Mode 1 is decided by the distribution center which issued the order at the latest. We can obtain the following from the deduction:

$$
\begin{aligned}
& E\left(\mathrm{CWT}_{g 1}\right) \leq \rho_{1} \\
& \cdot \min \left[\frac{\int_{0}^{+\infty} z_{i} g\left(z_{i}\right) d z_{i} \cdot \int_{0}^{I_{11}}\left[t_{w}-I_{11}+t\right] d t}{\int_{0}^{I_{11}} \int_{0}^{+\infty} z_{i} g\left(z_{i}\right) d z_{i} d t},\right. \\
& \left.\frac{\int_{0}^{+\infty} z_{i} g\left(z_{i}\right) d z_{i} \cdot \int_{0}^{I_{21}}\left[t_{w}-I_{21}+t\right] d t}{\int_{0}^{I_{21}} \int_{0}^{+\infty} z_{i} g\left(z_{i}\right) d z_{i} d t}\right] .
\end{aligned}
$$

According to (8), $E\left(\mathrm{CWT}_{g 1}\right) \leq \min \left(\mathrm{CWT}_{11}, \mathrm{CWT}_{21}\right)$ is established.

Conversely, In Mode 2, centralized distribution is adopted; the order can be delivered after receipting order requirements. If $s_{21}<s_{11} \leq t_{w}$ is established in the first delivery cycle, we can obtain $A_{11} \leq \mu_{1 t}$ and $A_{21}=\mu_{2 t}$. When orders of distribution center 2 are still generated between $s_{21}$ and $s_{11}, s_{21}<s_{g h 1} \leq s_{11}$ can be proved:

$$
\begin{aligned}
& E\left(\mathrm{CWT}_{g h 1}\right) \leq \rho_{1} \\
& \cdot \max \left[\frac{\int_{0}^{+\infty} z_{i} g\left(z_{i}\right) d z_{i} \cdot \int_{0}^{I_{11}}\left[t_{w}-I_{11}+t\right] d t}{\int_{0}^{I_{11}} \int_{0}^{+\infty} z_{i} g\left(z_{i}\right) d z_{i} d t},\right. \\
& \left.\frac{\int_{0}^{+\infty} z_{i} g\left(z_{i}\right) d z_{i} \cdot \int_{0}^{I_{21}}\left[t_{w}-I_{21}+t\right] d t}{\int_{0}^{I_{21}} \int_{0}^{+\infty} z_{i} g\left(z_{i}\right) d z_{i} d t}\right] .
\end{aligned}
$$

Combining (4) and (9), we can obtain $E\left(\mathrm{CWT}_{g h 1}\right) \leq$ $\max \left(\mathrm{CWT}_{11}, \mathrm{CWT}_{21}\right)$. By the same methods, $\min \left(E\left(\mathrm{CWT}_{11}\right)\right.$, $\left.E\left(\mathrm{CWT}_{21}\right)\right) \leq E\left(\mathrm{CWT}_{\text {gh1 }}\right) \leq \max \left(E\left(\mathrm{CWT}_{11}\right), E\left(\mathrm{CWT}_{21}\right)\right)$ can be proved. Therefore, considering above situations, $E\left(\mathrm{CWT}_{g 1}\right) \leq E\left(\mathrm{CWT}_{g h 1}\right)$ is established in the first delivery cycle.

However, when the delivery costs of two raw materials are linearly related; for example, we assume $z_{2}=a z_{1}+b$, $U_{2}=a U_{1}+b, U_{g h}=(a+1) U_{1}+b$, and we can obtain $s_{g h 1}=s_{11}=s_{21}$ and $\mathrm{CWT}_{g h 1}=\mathrm{CWT}_{11}=\mathrm{CWT}_{21}$. Due to the similar analyses in subsequent cycles, $\mathrm{CWT}_{g h j}=\mathrm{CWT}_{1 j}=$ $\mathrm{CWT}_{2 j}$ is established, meaning that the delivery time of the two modes can be the same in some cases. 


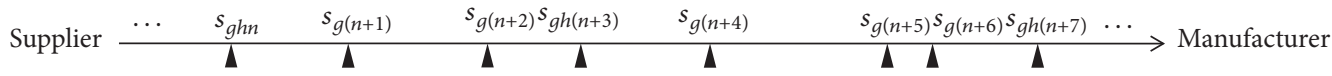

Figure 3: The CWT of two modes in subsequent delivery cycles (a).

Supplier $\begin{array}{ccccccc}\cdots & s_{g h(k+2)} & s_{g(k+3)} s_{g(k+4)} & s_{g(k+5)} s_{g h(k+6)} s_{g(k+7)} & s_{g(k+8)} & s_{g h(k+9)} & \cdots \\ & \boldsymbol{\Lambda} & \boldsymbol{\Lambda} & \boldsymbol{\Lambda} & \boldsymbol{\Lambda} & \boldsymbol{\Lambda} & \boldsymbol{\Lambda}\end{array}$

Figure 4: The CWT of two modes in subsequent delivery cycles (b).

2.3.2. The Flexibility Assessment of Two Distribution Modes in Subsequent Delivery Cycles. It has been argued that the relationship, $E\left(\mathrm{CWT}_{g j}\right)<E\left(\mathrm{CWT}_{g h j}\right)$, exists in the first delivery cycle. In order to facilitate the discussion, we select the interval from $s_{g h n}$ to $s_{g h(n+7)}$ and discuss the CWT of two modes, and the situation in other cycles can be made in similar analyses. Based on the characteristics of the two modes, we will discuss two types of cases in Figures 3 and 4 .

Considering the situation as shown in Figure 3, due to $s_{g h n}<s_{g(n+1)}$, Mode 1 cannot balance the asynchrony order delivery in these two periods. Equation (8) can be used for reference; the $\mathrm{CWT}_{g}{ }^{*}$ between $s_{g h n}$ and $s_{g h(n+7)}$ is as follows:

$$
\begin{aligned}
& \mathrm{CWT}_{g}{ }^{*} \\
& =\frac{\sum_{j=n}^{n+1} \rho_{j} \int_{0}^{+\infty} z_{i} g\left(z_{i}\right) d z_{i} \cdot \int_{s_{g j}}^{s_{g(j+1)}}\left[t_{w}-s_{g(j+1)}+t\right] d t}{\int_{s_{g n}}^{s_{g(n+2)}} \int_{0}^{+\infty} z_{i} g\left(z_{i}\right) d z_{i} d t} \\
& +\frac{\sum_{j=n+4}^{n+6} \rho_{j} \int_{0}^{+\infty} z_{i} g\left(z_{i}\right) d z_{i} \cdot \int_{s_{g j}}^{s_{g(j+1)}}\left[t_{w}-s_{g(j+1)}+t\right] d t}{\int_{s_{g(n+4)}}^{s_{g(n+7)}} \int_{0}^{+\infty} z_{i} g\left(z_{i}\right) d z_{i} d t} \\
& =\frac{1}{2}\left(s_{g n}+s_{g(n+7)}\right)+t_{w}-\frac{\sum_{j=n}^{n+1} s_{g(j+1)}\left[s_{g(j+1)}-s_{g j}\right]}{s_{g(n+2)}-s_{g n}} \\
& -\frac{\sum_{j=n+4}^{n+6} s_{g(j+1)}\left[s_{g(j+1)}-s_{g j}\right]}{s_{g(n+7)}-s_{g(n+4)}} .
\end{aligned}
$$

In Mode 2, supply hub coordinates the requirements of different channels through the establishment of a unified distribution center. Considering the integration capabilities of Mode 2 and (9), $\mathrm{CWT}_{g h}{ }^{*}$ between $s_{g h n}$ and $s_{g h(n+7)}$ is as follows:

$$
\begin{aligned}
& \mathrm{CWT}_{g h}{ }^{*} \\
& =\frac{\rho_{n+3} \int_{0}^{+\infty} z_{i} g\left(z_{i}\right) d z_{i} \cdot \int_{s_{g n}}^{s_{g(n+3)}}\left[t_{w}-s_{g(n+3)}+t\right] d t}{\int_{s_{g n}}^{s_{g(n+7)}} \int_{0}^{+\infty} z_{i} g\left(z_{i}\right) d z_{i} d t} \\
& +\frac{\rho_{n+7} \int_{0}^{+\infty} z_{i} g\left(z_{i}\right) d z_{i} \cdot \int_{s_{g(n+3)}}^{s_{g(n+7)}}\left[t_{w}-s_{g(n+7)}+t\right] d t}{\int_{s_{g n}}^{s_{g(n+7)}} \int_{0}^{+\infty} z_{i} g\left(z_{i}\right) d z_{i} d t} \\
& =\frac{1}{2}\left(s_{g n}+s_{g(n+7)}\right)+t_{w} \\
& -\frac{s_{g(n+3)}\left(s_{g(n+3)}-s_{g n}\right)+s_{g(n+7)}\left(s_{g(n+7)}-s_{g(n+3)}\right)}{s_{g(n+7)}-s_{g n}} .
\end{aligned}
$$

According to (10) and (11), we can obtain $\mathrm{CWT}_{g k}<$ $\mathrm{CWT}_{g h k}$. Their expectations still satisfy $E\left(\mathrm{CWT}_{g k}\right)<$ $E\left(\mathrm{CWT}_{g h k}\right)$. The more the cycles, the greater the gap between $E\left(\mathrm{CWT}_{g h k}\right)$ and $E\left(\mathrm{CWT}_{g k}\right)$. By (9) and (10), it can be seen that, in Mode 1, the whole time to complete the order delivery almost always lags behind that of Mode 2. In addition, the farther the distribution center with late order delivery lags behind, the smaller $E(C W T)$ of Mode 1 is.

Considering other situations as shown in Figure 4, $E\left(\mathrm{CWT}_{g k}\right)<E\left(\mathrm{CWT}_{g h k}\right)$ is also established by similar analytical methods. Due to the mutual independence of cycles and the similar process, referencing (1), we can estimate $E\left(\mathrm{CWT}_{i}\right)$ in general for each logistics service provider by $E\left(\mathrm{CWT}_{i}\right) \approx \sum_{j=1}^{n} A_{i j} E\left(\mathrm{CWT}_{i j}\right) / \sum_{j=1}^{n} A_{i j}, i=1,2$.

\section{Numerical Example and Discussion}

In this paper, the MATLAB simulation experiments are used to verify the performance of the proposed model. The maximum allowable waiting time $t_{w}$ is an exogenous variable and has no effect on the conclusions of the model.

3.1. The Sensitivity Analysis of Two Distribution Modes' CWT under Different $\gamma$ Value. In this section, two sets of data are randomly generated for sensitivity analysis as shown in Tables 1 and 2. We assume $t_{w}=20, \gamma=\varphi_{1} / \varphi_{2}, \varphi=\mu / \sigma$ ( $\varphi$ is the discrete coefficient, which represents the volatility degree of the order requirement). In Table $1, E\left(\mathrm{CWT}_{\text {Mode1 }}\right)$ decreases with increasing $\gamma$; however, the reflection of $E\left(\mathrm{CWT}_{\mathrm{Mode}_{2}}\right)$ on the change of $\gamma$ is opposite to $E\left(\mathrm{CWT}_{\text {Model }}\right)$. Furthermore, $E(\mathrm{CWT})$ changes of distribution center 1 and distribution center 2 are not obvious; this indicates that the difference of $\varphi$ value of the two distribution centers does affect $E\left(\mathrm{CWT}_{\text {Model }}\right)$ and the influence is more remarkable with $\gamma$ increasing dramatically. In comparison, $E\left(\mathrm{CWT}_{\text {Mode2 }}\right)$ is stable with the change of $\gamma$ or $\sigma_{2}$, meaning that Mode 2 is more robust than Mode 2.

As can be seen from Tables 1 and 2, E(CWT) of two modes are close with $\gamma=1.01$. However, if $\gamma$ increases slightly, $E\left(\mathrm{CWT}_{\text {Mode1 }}\right)$ 's change is larger than that of $E\left(\mathrm{CWT}_{\text {Mode2 }}\right)$; it also shows that, for $\gamma$ changes, $E\left(\mathrm{CWT}_{\text {Model }}\right)$ is more sensitive than $E\left(\mathrm{CWT}_{\mathrm{Mode}^{2}}\right)$. Even if the range variation of $\gamma$ value is small, the difference of $\varphi_{1}$ and $\varphi_{2}$ has a negative impact on $E\left(\mathrm{CWT}_{\text {Model }}\right)$.

3.2. The Comparative Analysis of Two Distribution Modes' CWT in Multidelivery Cycle. The three sets of parameters as 
TABLE 1: The CWT of two distribution modes with a large range variation of $\gamma$ value.

\begin{tabular}{lccccccccc}
\hline$\gamma$ & $\mu_{1}$ & $\sigma_{1}$ & $\mu_{2}$ & $\sigma_{2}$ & $E\left(\mathrm{CWT}_{\mathrm{DC1} 1}\right)$ & $E\left(\mathrm{CWT}_{\mathrm{DC} 2}\right)$ & $E\left(\mathrm{CWT}_{\mathrm{Model}}\right)$ & $E\left(\mathrm{CWT}_{\mathrm{Mode2} 2}\right)$ & $\frac{E\left(\mathrm{CWT} \mathrm{T}_{\text {Mode2 }}\right)-E\left(\mathrm{CWT} \mathrm{T}_{\mathrm{Model}}\right)}{E(\mathrm{CWT}}$ \\
\hline 0.75 & 10 & 1 & 80 & 6 & 15.55420 & 15.42347 & 15.36559 & 15.37879 & $0.09 \%$ \\
1.25 & 10 & 1 & 80 & 10 & 15.68923 & 15.68018 & 14.57412 & 15.61076 & $7.11 \%$ \\
1.75 & 10 & 1 & 80 & 14 & 15.56897 & 15.91892 & 14.06851 & 15.82809 & $12.51 \%$ \\
2.50 & 10 & 1 & 80 & 20 & 15.55332 & 16.24724 & 13.59938 & 16.12953 & $18.60 \%$ \\
3.13 & 10 & 1 & 80 & 25 & 15.66983 & 16.49683 & 13.05689 & 16.36068 & $25.30 \%$ \\
3.88 & 10 & 1 & 80 & 31 & 15.44521 & 16.77122 & 12.56897 & 16.61685 & $32.21 \%$ \\
4.50 & 10 & 1 & 80 & 36 & 15.77586 & 16.98143 & 11.98630 & 16.81454 & $40.28 \%$ \\
5.25 & 10 & 1 & 80 & 42 & 15.78963 & 16.51418 & 11.39865 & 16.93491 & $48.57 \%$ \\
\hline
\end{tabular}

Note. DC: distribution center.

TABLE 2: The CWT of two distribution modes with a small range variation of $\gamma$ value.

\begin{tabular}{lccccccccc}
\hline$\gamma$ & $\mu_{1}$ & $\sigma_{1}$ & $\mu_{2}$ & $\sigma_{2}$ & $E\left(\mathrm{CWT}_{\mathrm{DC1} 1}\right)$ & $E\left(\mathrm{CWT}_{\mathrm{DC} 2}\right)$ & $E\left(\mathrm{CWT}_{\text {Mode1 } 1}\right)$ & $E\left(\mathrm{CWT}_{\mathrm{Mode2}}\right)$ & $\frac{E\left(\mathrm{CWT} \mathrm{T}_{\text {Mode2 } 2}\right)-E\left(\mathrm{CWT} \mathrm{T}_{\mathrm{Model} 1}\right)}{E\left(\mathrm{CWT}_{\mathrm{Model}}\right)}$ \\
\hline 1.01 & 25 & 3 & 33 & 4.0 & 15.65535 & 15.66138 & 15.38645 & 15.39117 & $0.03 \%$ \\
1.09 & 25 & 3 & 33 & 4.3 & 15.48695 & 15.70632 & 15.04194 & 15.41887 & $2.51 \%$ \\
1.16 & 25 & 3 & 33 & 4.6 & 15.77586 & 15.75066 & 14.89632 & 15.44636 & $3.69 \%$ \\
1.31 & 25 & 3 & 33 & 5.2 & 15.28695 & 15.83764 & 14.58746 & 15.50069 & $6.26 \%$ \\
1.41 & 25 & 3 & 33 & 5.6 & 15.87951 & 15.89439 & 14.39987 & 15.53645 & $7.89 \%$ \\
1.54 & 25 & 3 & 33 & 6.1 & 15.69936 & 15.96398 & 14.13569 & 15.58064 & $10.22 \%$ \\
\hline
\end{tabular}

Note. DC: distribution center.

follows come from three distribution companies of Hongyunhonghe Group in Yunnan Province, China. The data of the first two lines for each table show the performance of the distribution company before using the supply hub mode. The data of the last line shows the performance of the distribution company adopting the supply hub mode.

As shown in Tables 3, 4, and 5, $E^{*}(\mathrm{CWT})=$ $\sum_{j=1}^{10} E\left(\mathrm{CWT}_{j}\right)$, it is the sum of the expected value of CWT and represents the flexibility of the system in all delivery cycles. Tables 3, 4, and 5 show that the delivery time of supply hub is in between two distribution centers' delivery time in any delivery cycle, which meets the requirements of $s_{2 j}<s_{g h j}<s_{1 j}$ and $I_{2 j} \leq I_{g h j} \leq I_{1 j}$. The correctness of $E\left(\mathrm{CWT}_{1}\right)<E\left(\mathrm{CWT}_{g h}\right)<E\left(\mathrm{CWT}_{2}\right)$ is proved by the calculation of $E^{*}(\mathrm{CWT})$. Even if $\varphi$ changes, $s_{2 j}<$ $s_{g h j}<s_{1 j}$ is still established. In general, $\min \left(I_{1 j}, I_{2 j}\right)<$ $I_{g h j}<\max \left(I_{1 j}, I_{2 j}\right)$ always exists in each delivery cycle. In the same table, comparing the supply hub and the distribution center with earlier delivery time, their delivery time is close. This shows that the pooling effect exists in the order delivery of supply hub mode [40].

\subsection{Discussion}

(1) In the sensitivity analysis, Mode 2 shows greater robustness that the change of $E\left(\mathrm{CWT}_{\text {Mode2 }}\right)$ is smaller than that of $E\left(\mathrm{CWT}_{\text {Model }}\right)$ with the increase of $\gamma$. The overlapping time makes $E\left(\mathrm{CWT}_{\text {Mode1 }}\right)$ greatly reduce, and the centralized distribution of Mode 2 effectively avoids the occurrence of this situation; hence the Mode 2 is relatively stable in delivery flexibility.
(2) It is pointed out that the supply hub mode has obvious pooling effect on inventory problem [40], and the example analysis in Section 3 shows that the supply hub mode also has pooling effect on delivery problem. It may be that Mode 2 can obtain a larger CWT stably by balancing the demand-side fluctuations of two kinds of raw material. The pooling effect makes Mode 2 arrange the order delivery reasonably to achieve the scale economy.

(3) The distribution of delivery intervals between the suppliers is similar, but the distribution of delivery time is independent. As shown in Tables 1 and 2, the flexibility of Mode 1 decreases with the increasing differences of dispersion degree $(\gamma)$ of two distribution centers' delivery costs. Unlike Mode 1, Mode 2 focuses on the raw material of each supplier and arranges the delivery in a centralized manner to ensure that the raw materials can be sent to manufacturer at the same time. These features help Model 2 effectively avoid the impact of asynchronous delivery time of the same batch order and improve the stability of the system's CWT.

(4) Summarizing the above discussion, E(CWT) of Mode 2 is obviously greater than that of Mode 1 in all delivery cycles. In other words, the supply hub is more flexible than decentralized distribution mode. In addition, it should be noted that there is no point in discussing CWT when the fluctuations in delivery cost of raw materials are small (this means that 
TABLE 3: $I_{i j}$ and $E(C W T)$ of two modes with $\mu_{1}=14, \sigma_{1}=4, \mu_{2}=33, \sigma_{2}=12, t_{w}=20$.

\begin{tabular}{lcccccccccc}
\hline Logistics service provider & $I_{i 1}$ & $I_{i 2}$ & $I_{i 3}$ & $I_{i 4}$ & $I_{i 5}$ & $I_{i 6}$ & $I_{i 7}$ & $I_{i 8}$ & $I_{i 9}$ & $E^{*}(\mathrm{CWT})$ \\
\hline Distribution center 1 & 28 & 61 & 89 & 114 & 145 & 173 & 201 & 229 & 257 & 14.66853 \\
Distribution center 2 & 29 & 57 & 90 & 117 & 149 & 177 & 210 & 240 & 269 & 15.68531 \\
Supply hub & 30 & 60 & 89 & 115 & 146 & 175 & 203 & 231 & 259 & 15.22587 \\
\hline
\end{tabular}

TABLE 4: $I_{i j}$ and $E(C W T)$ of two modes with $\mu_{1}=16, \sigma_{1}=5, \mu_{2}=35, \sigma_{2}=15, t_{w}=20$.

\begin{tabular}{lcccccccccc}
\hline Logistics service provider & $I_{i 1}$ & $I_{i 2}$ & $I_{i 3}$ & $I_{i 4}$ & $I_{i 5}$ & $I_{i 6}$ & $I_{i 7}$ & $I_{i 8}$ & $I_{i 9}$ & $E^{*}(\mathrm{CWT})$ \\
\hline Distribution center 1 & 38 & 60 & 93 & 128 & 166 & 203 & 239 & 277 & 302 & 18.85637 \\
Distribution center 2 & 40 & 65 & 98 & 133 & 170 & 209 & 248 & 289 & 316 & 20.25938 \\
Supply hub & 39 & 61 & 94 & 130 & 168 & 204 & 242 & 280 & 305 & 19.58786 \\
\hline
\end{tabular}

TABLE 5: $I_{i j}$ and $E(C W T)$ of two modes with $\mu_{1}=15, \sigma_{1}=8, \mu_{2}=30, \sigma_{2}=20, t_{w}=20$.

\begin{tabular}{lcccccccccc}
\hline Logistics service provider & $I_{i 1}$ & $I_{i 2}$ & $I_{i 3}$ & $I_{i 4}$ & $I_{i 5}$ & $I_{i 6}$ & $I_{i 7}$ & $I_{i 8}$ & $I_{i 9}$ & $E^{*}(\mathrm{CWT})$ \\
\hline Distribution center 1 & 37 & 60 & 97 & 134 & 171 & 208 & 245 & 282 & 319 & 20.89623 \\
Distribution center 2 & 39 & 63 & 102 & 141 & 180 & 219 & 258 & 297 & 336 & 23.68952 \\
Supply hub & 38 & 61 & 98 & 135 & 173 & 210 & 247 & 284 & 323 & 22.57841 \\
\hline
\end{tabular}

order for each delivery is homogeneous and the same amount) or $g_{i}\left(z_{i}\right)$ is determined.

\section{Conclusions}

In this paper, we establish a new method of flexibility assessment in distribution hub by introducing cost weighted time. First, we assume that there is a simple supply chain structure of 1 manufacturer and 2 suppliers; each distribution center of Mode 1 only delivers one raw material. Furthermore, we compare and analyze $E(\mathrm{CWT})$ of supply hub mode and decentralized distribution mode in the first delivery cycles, and the analysis results are extended to the subsequent delivery cycles. Finally, we prove that the supply hub has pooling effect on delivery problem and is more flexible than decentralized distribution mode in every deliver cycle.

This paper contributes to existing research in two ways: (i) most of the researches only defined the definition and condition of delivery flexibility or used delivery flexibility as one of the assessment indicators to solve other problems; they did not give a method to determine the delivery flexibility under known distribution center operation mode. In this paper, the flexibility performance of decentralized distribution mode and supply hub operation mode (Mode 2) are compared and analyzed. By the proposed assessment method, we show that Mode 2 is more flexible than Mode 1 due to the better performance in balancing different delivery time. (ii) Comparing with [33], which did not consider the delivery cost weight of the order by using the slack time, we propose the cost weighted time by introducing the delivery cost of order into slack time that can be more accurate to measure the effect of delivery cost on the delivery time. The numerical example and analytical results indicate the usefulness and practicality of the proposed method.
Finally, our study has some limitations. For example, this paper sets up various constraints for the new model, such as the constraints of the numbers of suppliers and orders' variety and the fluctuations in delivery cost and the delivery time. If these constraints change, the generating function of $E(C W T)$ will change correspondingly. This may make the model more complex and may not provide a complete solution. Therefore, future research should focus on loosening the constraints of the logistics distribution hub model so that it is more adaptable to the actual situation.

\section{Notation and Definitions}

$i$ : The sequence number of logistics service provider; it also represents different patterns in some cases, $i=g$ means Mode 1 and $i=g h$ means Mode 2

$j$ : The sequence number of order, $j=1,2, \ldots, m$

$t_{w}$ : The maximum allowable waiting time of an order that delivery can be triggered

$U_{i}$ : The ideal delivery cost of raw materials that delivery can be triggered by logistics service provider

$z_{i}$ : The acceptable delivery cost of raw material for manufacturer per unit time; it obeys the normal distribution of variance $\sigma_{i}$, and its mean value and probability density function are $\mu_{i}$ and $g_{i}\left(z_{i}\right)$

$z_{i t}$ : The acceptable delivery cost of raw material for manufacturer per $t_{w}$; it obeys the normal distribution of variance $\sigma_{i t}$, and its mean value and probability density function are $\mu_{i t}$ and $g_{i t}\left(z_{i}\right)$ 
$t^{*}: \quad$ The waiting time of the first order that is waiting time less than $t_{w}$

$I_{i j}$ : The delivery time interval of logistics service provider $i$ between order $j-1$ and order $j$

$A_{i j}: \quad$ The delivery cost of logistics service provider $i$ in $j$ th delivery cycle

$s_{i j}$ : The total delivery time of logistics service provider $i$ before delivering orders $j+1$, $s_{i k}=\sum_{k=1}^{j} I_{i k}$

$\varphi_{i}: \quad$ The discrete coefficient of distribution of $z_{i j}$

$\rho_{j}: \quad$ The delivery satisfaction factor of order $j$

$C_{j}: \quad$ The delivery cost of order $j$

$\mathrm{LDT}_{j}$ : The latest delivery time of order $j$ required by customer

$\mathrm{ET}_{j}$ : The earliest time of order $j$ that delivery can be triggered

CWT: The cost weighted time

F: $\quad$ The weighted distribution flexibility.

\section{Conflicts of Interest}

The authors declare that there are no conflicts of interest regarding the publication of this paper.

\section{Acknowledgments}

The work described in this paper is supported by the National Natural Science Foundation Council of China under Projects no. 71661029 and no. 71502159; the Applied Basic Research Science Foundation of Yunnan Provincial Department of Science and Technology in China under Project no. 2015FD028; and the Science and Technology Innovation Team Fund of Logistics Engineering in Colleges and Universities of Yunnan Province, China.

\section{References}

[1] E. Kreutzberger and R. Konings, "The challenge of appropriate hub terminal and hub-and-spoke network development for seaports and intermodal rail transport in Europe," Research in Transportation Business and Management, vol. 19, pp. 83-96, 2016.

[2] S. Lan, C. Yang, and G. Q. Huang, "Data analysis for metropolitan economic and logistics development," Advanced Engineering Informatics, vol. 32, pp. 66-76, 2017.

[3] A. Ebrahimi-zade, H. Hosseini-Nasab, Y. zare-mehrjerdi, and A. Zahmatkesh, "Multi-period hub set covering problems with flexible radius: a modified genetic solution," Applied Mathematical Modelling. Simulation and Computation for Engineering and Environmental Systems, vol. 40, no. 4, pp. 2968-2982, 2016.

[4] M. Mohammadi, R. Tavakkoli-Moghaddam, A. Siadat, and J.Y. Dantan, "Design of a reliable logistics network with hub disruption under uncertainty," Applied Mathematical Modelling. Simulation and Computation for Engineering and Environmental Systems, vol. 40, no. 9-10, pp. 5621-5642, 2016.
[5] I. Correia, S. Nickel, and F. Saldanha-da-Gama, "A stochastic multi-period capacitated multiple allocation hub location problem: Formulation and inequalities," Omega (United Kingdom), 2016.

[6] I. Essaadi, B. Grabot, and P. Fénies, "Location of logistics hubs at national and subnational level with consideration of the structure of the location choice," IFAC-PapersOnLine, vol. 49, no. 31, pp. 155-160, 2016.

[7] A. Ghodratnama, R. Tavakkoli-Moghaddam, and A. Azaron, "Robust and fuzzy goal programming optimization approaches for a novel multi-objective hub location-allocation problem: A supply chain overview," Applied Soft Computing Journal, vol. 37, pp. 255-276, 2015.

[8] K. Yang, L. Yang, and Z. Gao, "Planning and optimization of intermodal hub-and-spoke network under mixed uncertainty," Transportation Research Part E: Logistics and Transportation Review, vol. 95, pp. 248-266, 2016.

[9] Y. Wang, X. Ma, M. Xu, Y. Liu, and Y. Wang, “Two-echelon logistics distribution region partitioning problem based on a hybrid particle swarm optimization-genetic algorithm," Expert Systems with Applications, vol. 42, no. 12, pp. 5019-5031, 2015.

[10] T. Anwar, C. Liu, H. L. Vu, and C. Leckie, "Partitioning road networks using density peak graphs: Efficiency vs. accuracy," Information Systems, vol. 64, pp. 22-40, 2017.

[11] A. Franceschetti, D. Honhon, G. Laporte, T. V. Woensel, and J. C. Fransoo, "Strategic fleet planning for city logistics," Transportation Research Part B: Methodological, vol. 95, pp. 1940, 2017.

[12] K. Bichou and R. Gray, "A logistics and supply chain management approach to port performance measurement," Maritime Policy and Management, vol. 31, no. 1, pp. 47-67, 2004.

[13] K. Bichou, "Chapter 24 review of port performance approaches and a supply chain framework to port performance benchmarking," Research in Transportation Economics, vol. 17, pp. 567-598, 2006.

[14] C. P. Barros and P. U. C. Dieke, "Measuring the economic efficiency of airports: A Simar-Wilson methodology analysis," Transportation Research Part E: Logistics and Transportation Review, vol. 44, no. 6, pp. 1039-1051, 2008.

[15] M. C. B. Cheng and J. J. Wang, "An integrative approach in measuring hub-port supply chain performance: Potential contributions of a logistics and transport data exchange platform," Case Studies on Transport Policy, vol. 4, no. 2, pp. 150-160, 2016.

[16] G. Anand and P. T. Ward, "Fit, flexibility and performance in manufacturing: Coping with dynamic environments," Production and Operations Management, vol. 13, no. 4, pp. 369-385, 2004.

[17] M. Swafford Patricia et al., "A framework for assessing value chain agility," International Journal of Operations and Production Management, vol. 26, no. 2, pp. 118-140.

[18] P. C. Patel, "Role of manufacturing flexibility in managing duality of formalization and environmental uncertainty in emerging firms," Journal of Operations Management, vol. 29, no. 1-2, pp. 143-162, 2011.

[19] W. C. Jordan and S. C. Graves, "Principles on the benefits of manufacturing process flexibility," Management Science, vol. 41, no. 4, pp. 577-594, 1995.

[20] S. Nigel, "The flexibility of manufacturing systems," International Journal of Operations and Production Management, vol. 7, no. 4, pp. 35-45.

[21] D. M. Upton, "The Management of Manufacturing Flexibility," California Management Review, vol. 36, no. 2, pp. 72-89, 1994. 
[22] V. Grover and M. K. Malhotra, "Transaction cost framework in operations and supply chain management research: Theory and measurement," Journal of Operations Management, vol. 21, no. 4, pp. 457-473, 2003.

[23] B. Mansoornejad, V. Chambost, and P. Stuart, "Integrating product portfolio design and supply chain design for the forest biorefinery," Computers and Chemical Engineering, vol. 34, no. 9, pp. 1497-1506, 2010.

[24] L. G. Papageorgiou, "Supply chain optimisation for the process industries: advances and opportunities," Computers and Chemical Engineering, vol. 33, no. 12, pp. 1931-1938, 2009.

[25] B. H. Gebreslassie, Y. Yao, and F. You, "Design under uncertainty of hydrocarbon biorefinery supply chains: Multiobjective stochastic programming models, decomposition algorithm, and a Comparison between CVaR and downside risk," AIChE Journal, vol. 58, no. 7, pp. 2155-2179, 2012.

[26] F. You, J. M. Wassick, and I. E. Grossmann, "Risk management for a global supply chain planning under uncertainty: Models and algorithms," AIChE Journal, vol. 55, no. 4, pp. 931-946, 2009.

[27] K.-H. Chang and H.-F. Huang, "Using influence strategies to advance supplier delivery flexibility: The moderating roles of trust and shared vision," Industrial Marketing Management, vol. 41, no. 5, pp. 849-860, 2012.

[28] Y. Li, G. Nemhauser, and M. Savelsbergh, "Pricing for production and delivery flexibility in single-item lot-sizing," Computers and Operations Research, vol. 39, no. 12, pp. 3408-3419, 2012.

[29] Y.-Y. Chen, "Fuzzy flexible delivery and pickup problem with time windows," in Proceedings of the 1st International Conference on Information Technology and Quantitative Management, ITQM 2013, pp. 379-386, chn, May 2013.

[30] Z. Li, X. Wang, and N. Zheng, "An evaluation model for synchronized supply chain based on entropy weight and TOPSIS I," Advances in Intelligent and Soft Computing, vol. 115, no. 2, pp. 787-793, 2012.

[31] B. Kocaoğlu, B. Gülsün, and M. Tanyaş, "A SCOR based approach for measuring a benchmarkable supply chain performance," Journal of Intelligent Manufacturing, vol. 24, no. 1, pp. 113-132, 2013.

[32] M. Ha, Z. Yang, T. Notteboom, A. K. Ng, and M. Heo, "Revisiting port performance measurement: A hybrid multistakeholder framework for the modelling of port performance indicators," Transportation Research Part E: Logistics and Transportation Review, vol. 103, pp. 1-16, 2017.

[33] B. M. Beamon, "Measuring supply chain performance," International Journal of Operations and Production Management, vol. 19, no. 3, pp. 275-292, 1999.

[34] J. Shah and M. Goh, "Setting operating policies for supply hubs," International Journal of Production Economics, vol. 100, no. 2, pp. 239-252, 2006.

[35] Z. Belalia and F. Ghaiti, "The value of Vendor Managed Inventory in an autocorrelated demand environment," IFACPapersOnLine, vol. 49, no. 12, pp. 668-673, 2016.

[36] H. Chaudhry and G. Hodge, "Vendor-managed inventory systems in the apparel industry," Information Systems for the Fashion and Apparel Industry, pp. 221-234, 2016.

[37] A. Mateen and A. K. Chatterjee, "Vendor managed inventory for single-vendor multi-retailer supply chains," Decision Support Systems, vol. 70, pp. 31-41, 2015.

[38] S. Çetinkaya and C.-Y. Lee, "Stock replenishment and shipment scheduling for vendor-managed inventory systems," Management Science, vol. 46, no. 2, pp. 217-232, 2000.
[39] T. Wang and B. L. Toktay, "Inventory management with advance demand information and flexible delivery," Management Science, vol. 54, no. 4, pp. 716-732, 2008.

[40] A. Eynan and T. Fouque, "Capturing the risk-pooling effect through demand reshape," Management Science, vol. 49, no. 6, pp. 704-717, 2003. 


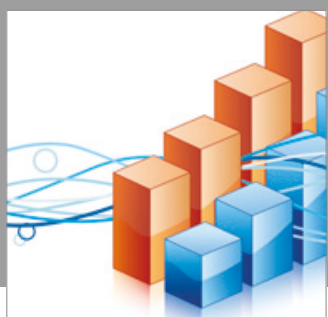

Advances in

Operations Research

vatersals

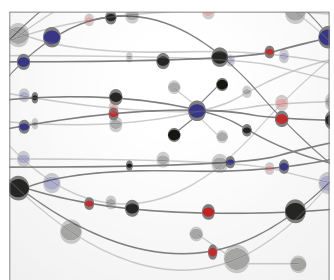

\section{The Scientific} World Journal
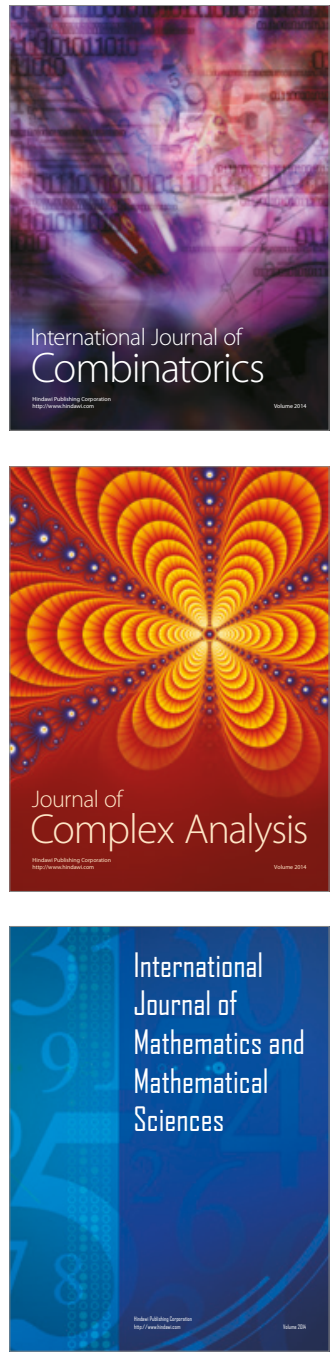
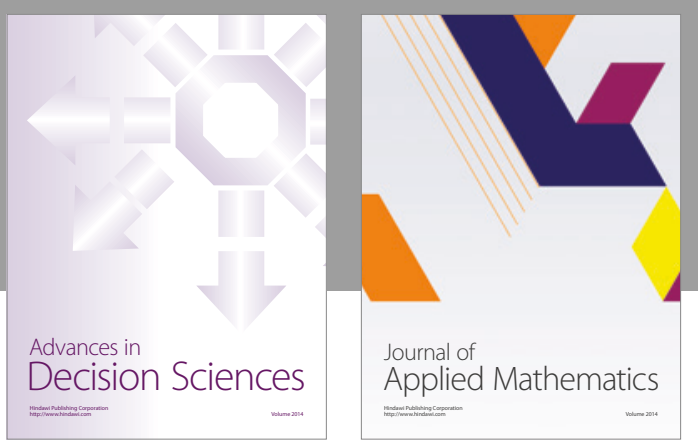

Algebra

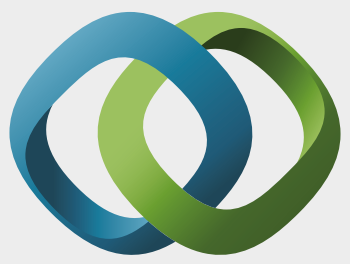

\section{Hindawi}

Submit your manuscripts at

https://www.hindawi.com
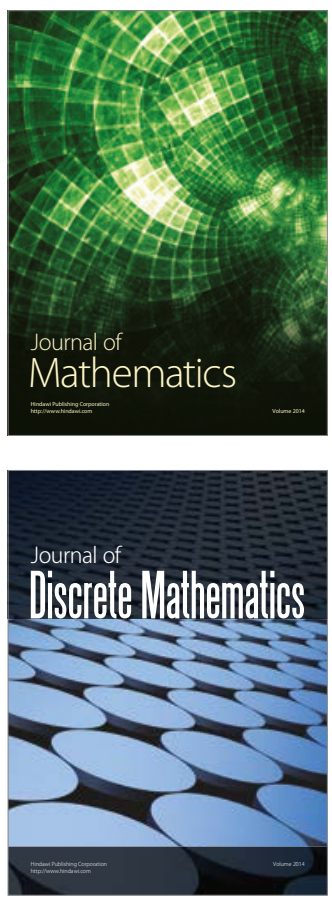

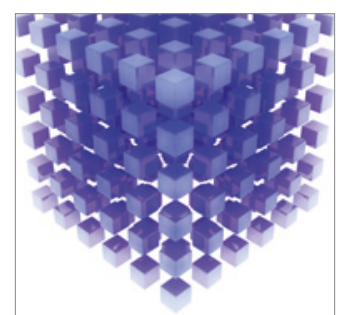

Mathematical Problems in Engineering
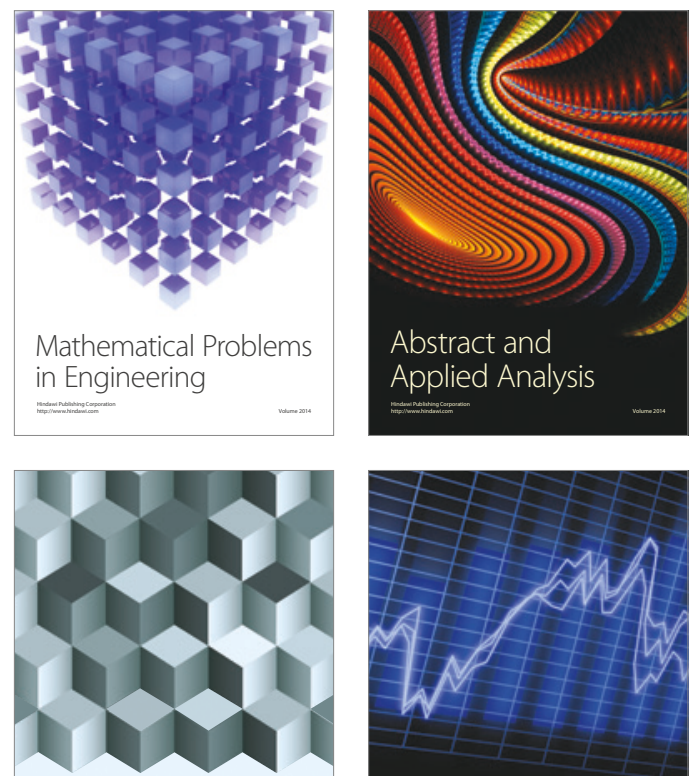

Journal of

Function Spaces

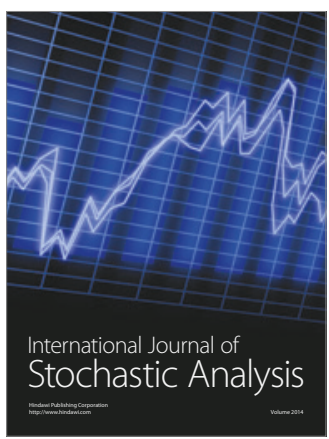

Probability and Statistics
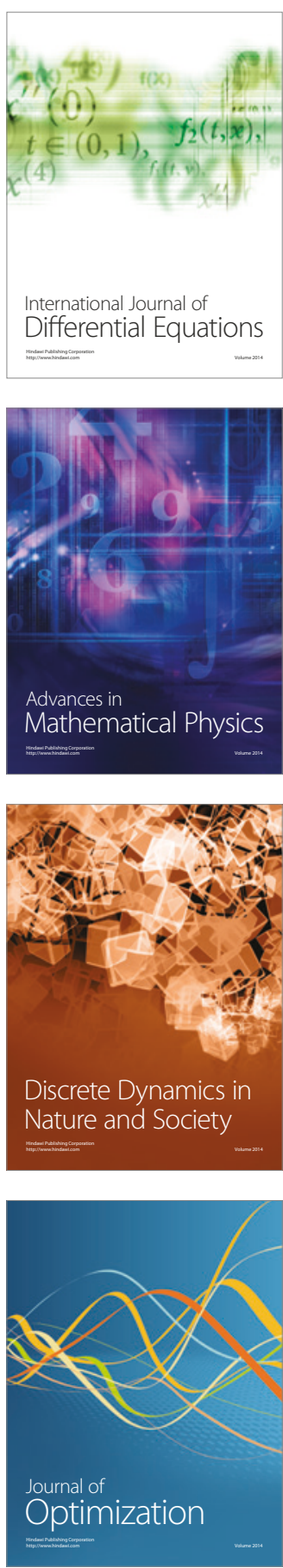